\title{
Galantamine-Memantine Combination and Kynurenine Pathway Enzyme Inhibitors in the Treatment of Neuropsychiatric Disorders
}

\author{
Michael Y. Bai ${ }^{a}$ David B. Lovejoy ${ }^{a}$ Gilles J. Guillemin ${ }^{a}$ Rouba Kozak ${ }^{b}$ \\ Trevor W. Stone ${ }^{c}$ Maju Mathew Koolad \\ aDepartment of Biomedical Sciences, Neuroinflammation Group, Macquarie University Centre for Motor Neuron \\ Disease Research, Faculty of Medicine, Health and Human Sciences, Macquarie University, Sydney, NSW, Australia; \\ ${ }^{\mathrm{b}}$ Neuroscience Drug Discovery Unit, Takeda Pharmaceuticals International Co, Cambridge, MA, USA; ${ }^{\mathrm{N}}$ (uffield \\ Department of Orthopedics, Rheumatology and Musculoskeletal Sciences (NDORMS), University of Oxford, Oxford, \\ UK; d Department of Psychiatry and Behavioral Health, Stony Brook University Renaissance School of Medicine, \\ Stony Brook, Stony Brook, NY, USA
}

\section{Keywords}

Kynurenine $\cdot$ Kynurenic acid $\cdot$ Enzyme inhibitors .

Galantamine $\cdot$ Memantine $\cdot$ Neuropsychiatric diseases

\begin{abstract}
The kynurenine pathway (KP) is a major route for L-tryptophan (L-TRP) metabolism, yielding a variety of bioactive compounds including kynurenic acid (KYNA), 3-hydroxykynurenine (3-HK), quinolinic acid (QUIN), and picolinic acid (PIC). These tryptophan catabolites are involved in the pathogenesis of many neuropsychiatric disorders, particularly when the KP becomes dysregulated. Accordingly, the enzymes that regulate the KP such as indoleamine 2,3-dioxygenase (IDO)/tryptophan 2,3-dioxygenase, kynurenine aminotransferases (KATs), and kynurenine 3-monooxygenase $(\mathrm{KMO})$ represent potential drug targets as enzymatic inhibition can favorably rebalance KP metabolite concentrations. In addition, the galantamine-memantine combination, through its modulatory effects at the alpha7 nicotinic acetylcholine receptors and N-methyl-D-aspartate receptors, may counteract the effects of KYNA. The aim of this review is to highlight the effectiveness of IDO-1, KAT II, and $\mathrm{KMO}$ inhibitors, as well as the galantamine-memantine com-
\end{abstract}

karger@karger.com

(c) 2021 S. Karger AG, Base

www.karger.com/cxp

Karger" bination in the modulation of different KP metabolites. KAT II inhibitors are capable of decreasing the KYNA levels in the rat brain by a maximum of $80 \%$. KMO inhibitors effectively reduce the central nervous system (CNS) levels of 3-HK, while markedly boosting the brain concentration of KYNA. Emerging data suggest that the galantamine-memantine combination also lowers L-TRP, kynurenine, KYNA, and PIC levels in humans. Presently, there are only 2 pathophysiological mechanisms (cholinergic and glutamatergic) that are FDA approved for the treatment of cognitive dysfunction for which purpose the galantamine-memantine combination has been designed for clinical use against Alzheimer's disease. The alpha7 nicotinic-NMDA hypothesis targeted by the galantamine-memantine combination has been implicated in the pathophysiology of various CNS diseases. Similarly, KYNA is well capable of modulating the neuropathophysiology of these disorders. This is known as the KYNA-centric hypothesis, which may be implicated in the management of certain neuropsychiatric conditions. In line with this hypothesis, KYNA may be considered as the "conductor of the orchestra" for the major pathophysiological mechanisms underlying CNS disorders. Therefore, there is great opportunity to further explore and compare the biological effects of these therapeutic modalities in animal models with a special 
focus on their effects on KP metabolites in the CNS and with the ultimate goal of progressing to clinical trials for many neuropsychiatric diseases.

(c) 2021 S. Karger AG, Basel

\section{Introduction}

L-Tryptophan (L-TRP), an essential amino acid, can be transported into the central nervous system (CNS) across the blood-brain barrier (BBB) via L-amino acid transporter 1 (LAT-1). Once it gains entry into the brain, L-TRP can be utilized in the biosynthesis of serotonin, but a major proportion of the amino acid is incorporated into the kynurenine pathway $(\mathrm{KP})[1-3]$, thereby producing a number of bioactive metabolites, including kynurenine (KYN), kynurenic acid (KYNA), quinolinic acid (QUIN), and picolinic acid (PIC) [4]. Although KYNA has been described as neuroprotective $[5,6]$, there is growing evidence that the majority of KP metabolites play a substantial role in the pathogenesis of a number of neuropsychiatric diseases $[7,8]$, including schizophrenia [9-11], depression [12$14]$, Parkinson's disease (PD) $[15,16]$, bipolar disorder $[11,17]$, Huntington's disease (HD) [18], multiple sclerosis [19], and Alzheimer's disease (AD) [18, 20], particularly when the KP becomes dysregulated.

A number of enzymes have been associated with the $\mathrm{KP}$, as shown in Fig. 1. Indoleamine/tryptophan 2,3-dioxygenase (IDO-1/TDO) catalyzes the first step, followed by the other major enzymes: kynurenine aminotransferases (KATs) and kynurenine monooxygenase (KMO) [21]. Animal studies indicate that the inhibition of these KP enzymes can have a beneficial therapeutic effect in neurological diseases through reduction of the levels of neurotoxic KP metabolites within the brain [22, 23]. As evidence suggests, the FDA-approved medications galantamine (acetylcholinesterase inhibitor and positive allosteric modulator of $\alpha 7 \mathrm{nACh}$ receptors) and memantine (although classified as an antagonist, acts as an NMDA receptor modulator/glutamate receptor agonist, paradoxically $[20,24-26])$ are well known for their effectiveness in various neuropsychiatric disorders [27]. However, recent clinical evidence [28] also hints at the possible role of these medications in decreasing KYNA levels, which can be particularly beneficial for patients with schizophrenia. These early data have set the stage for increasing recognition of their potential role in the therapeutic modulation of the KP (Fig. 1). To better target and reduce KYNA levels, KAT II and KMO inhibitors with the galantaminememantine combination have been proposed as a poten-

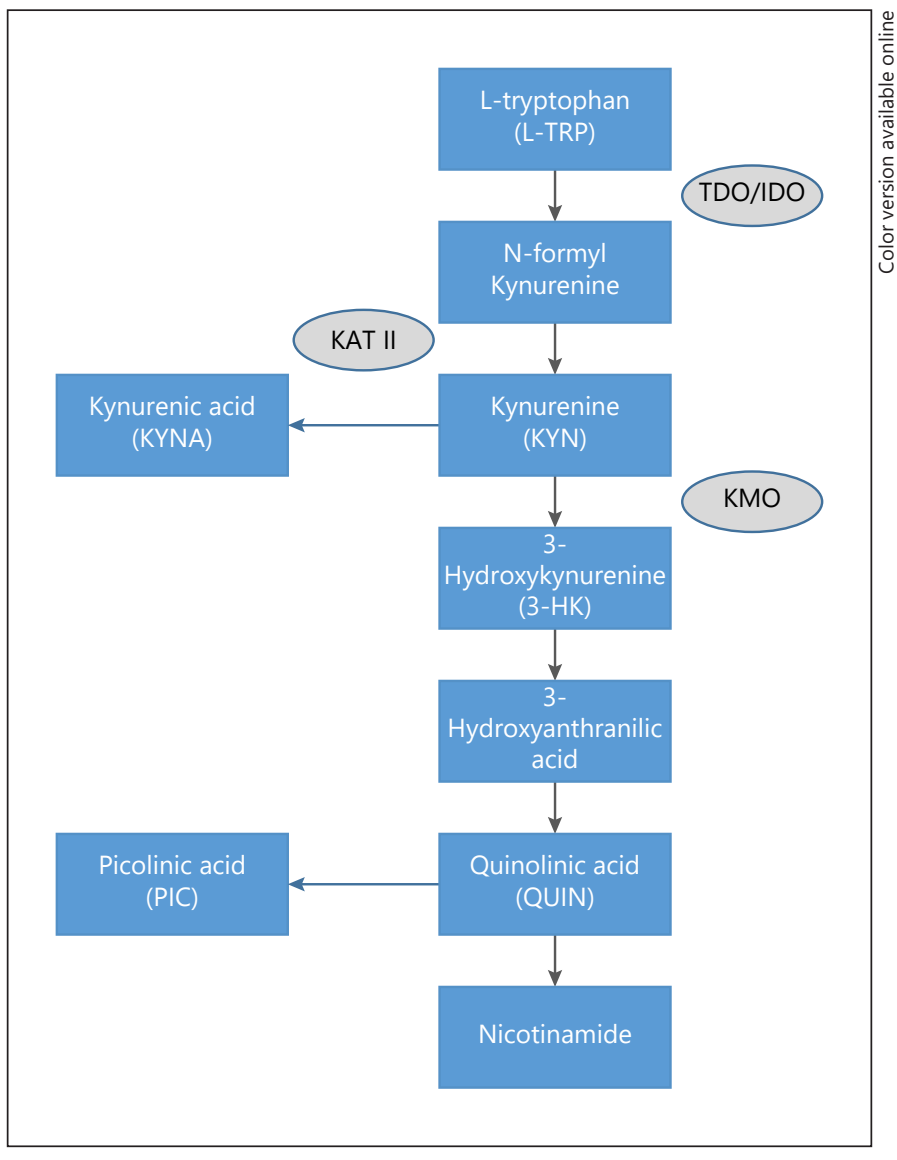

Fig. 1. Four major enzymes acting in the KP. KYN, kynurenine; $\mathrm{KP}$, kynurenine pathway; 3-HK, 3-hydroxykynurenine; L-TRP, Ltryptophanl; KAT, kynurenine aminotransferase; PIC, picolinic acid; KMO, kynurenine monooxygenase; IDO, indoleamine 2,3-dioxygenase; TDO, tryptophan 2,3-dioxygenase.

tial new therapeutic tool to alleviate cognitive impairments in various neuropsychiatric diseases [21,29].

The aim of this review is to evaluate the current and future prospects with regard to the potential of this novel drug combination to favorably modulate KP.

\section{Role of KP Metabolites in the Pathogenesis of \\ Neuropsychiatric Disorders}

The potential role of KYNA in the pathogenesis of schizophrenia [30-33] has been widely studied. Excess KYNA is associated with schizophrenia through 2 different signaling pathways. First, KYNA is a known NMDA antagonist, and decreased glutamatergic activity at the NMDA receptors is at the center of schizophrenia pathogenesis [34]. The glutamatergic nervous system for a possible therapeutic strategy in mood disorders has been discussed recently [35]. In addition, Erhardt et al. [36] also 
found a positive correlation between elevated brain KYNA levels and an increase in CNS dopaminergic activity. Hence, KYNA potentiates dopaminergic neurons, which provides a possible mechanistic link between KYNA and the development of schizophrenia [37]. There is, however, some contraindication to this belief $[38,39]$ as some researchers have indicated that KYNA leads to a drop in CNS dopamine levels, which is possibly mediated by its inhibitory effect on the responses to $\alpha 7 \mathrm{nACh}$ receptor activation. Another important aspect of schizophrenia is a decline in the CNS GABAergic activity [40] where KYNA has been found to negatively influence the overall GABAmediated neurotransmission within the brain [41].

Nicotinic receptor activity in the CNS ( $\alpha 7 n A C h R)$ has also been found to be downregulated due to increased KYNA levels [42, 43]. However, this theory still remains highly controversial as to whether any interaction is direct or indirect $[44,45]$. Irrespective of its negative role in neuropsychiatric disorders, KYNA has been shown to play a neuroprotective role in $\mathrm{HD}, \mathrm{AD}, \mathrm{PD}$, and other neurodegenerative disorders through its NMDA-antagonist activity [46-48]. On the contrary, elevated QUIN levels lead to excitotoxic stimulation of NMDA receptors in the glutamatergic pathway in HD [49]. Moreover, a substantially reduced KYNA/QUIN ratio has been found in patients with AD [50].

KYNA has been reported to possess an antioxidant activity [51], and as an agonist at aryl hydrocarbon receptors [52], it plays a key role in the regulation of neuroinflammation by altering the balance between proinflammatory and anti-inflammatory immune mediators [53]. Therefore, KYNA levels bidirectionally modulate the concentrations of glutamate [54], dopamine [55], and GABA $[56,57]$ as well as the redox and neuroinflammatory systems [51,57-60]. KYNA is the conductor of the orchestra of the major pathophysiological mechanisms (Fig. 2). This is known as the KYNA-centric pathophysiology [24], as shown in Fig. 2. The KYNA-centric hypothesis has only been published recently [61]. Additionally, KYNA as well as other KP catabolites have been extensively identified as tolerogenic molecules in the milieu of cancer pathogenesis [62-65].

\section{Involvement of KP Metabolites in Neurocognitive \\ Impairment}

The pathological implications of KP metabolites in the impairment of cognitive function have become increasingly evident in recent years. Animal models have demonstrated that increased brain KYNA concentrations can significantly impair major cognitive skills [66], such as

Galantamine-Memantine Combination and KP Enzyme Inhibitors for

Neuropsychiatric Diseases

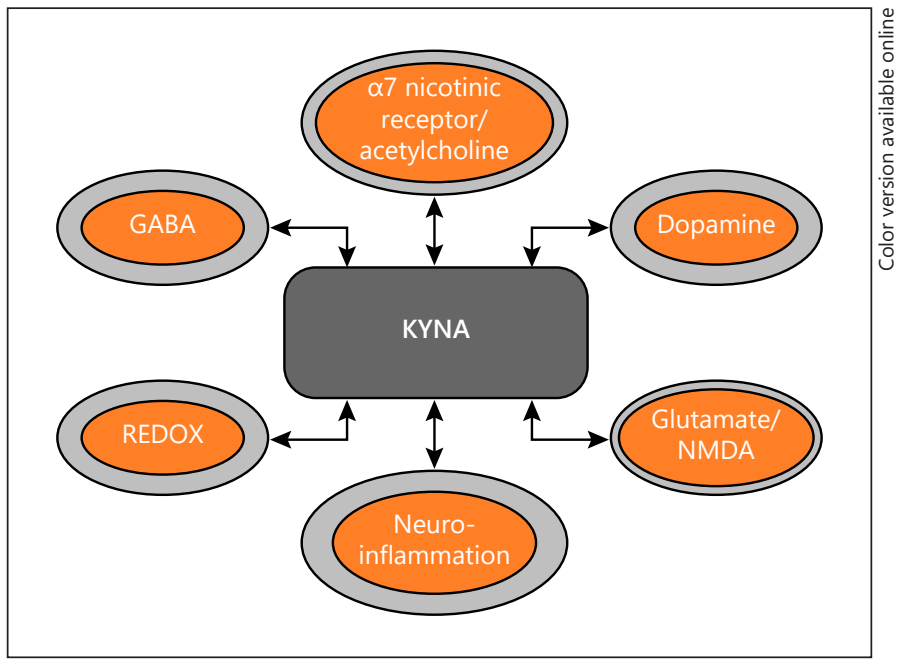

Fig. 2. KYNA bidirectionally modulates the levels of dopamine, acetylcholine, glutamate, and GABA as well as the redox and neuroinflammatory systems. This is known as the KYNA-centric hypothesis. KYNA is the conductor of the orchestra of the major pathophysiological mechanisms of many CNS disorders. KYNA, kynurenic acid; CNS, central nervous system.

short-term working memory, conditioned reflexes, and other learning capabilities of the animal subjects $[67,68]$. The commonly proposed underlying mechanisms involve the inhibitory impact of KYNA on the excitatory NMDA receptors and probably indirectly on $\alpha 7 \mathrm{nAChR}$ [55]. Apart from animal studies, data derived from human populations have also revealed a significant correlation between elevated serum KYN/L-TRP ratio (indicative of inflammation-driven KP induction) and a progressively poor cognitive function $[69,70]$. A possible association between aging and raised KYN/L-TRP ratio, accompanied by a poor mental capacity, was first hinted by RamosChávez et al. [71]. Besides KYN/L-TRP, a progressively rising KYNA/QUIN ratio has also been strongly linked with a poor cognitive performance in cases of schizophrenia. Interestingly, some contrasting findings have been reported regarding this matter [72] wherein a few authors propose that a higher KYNA/QUIN ratio arises due to elevated CSF KYNA levels [9], while others opine that it may be due to a lower QUIN concentration [73].

\section{Enzymatic Inhibitors of the KP}

\section{IDO/TDO Inhibitors}

$\mathrm{IDO} / \mathrm{TDO}$ enzymes initiate the KP by catalyzing the synthesis of KYN from L-TRP. TDO is mostly associated 


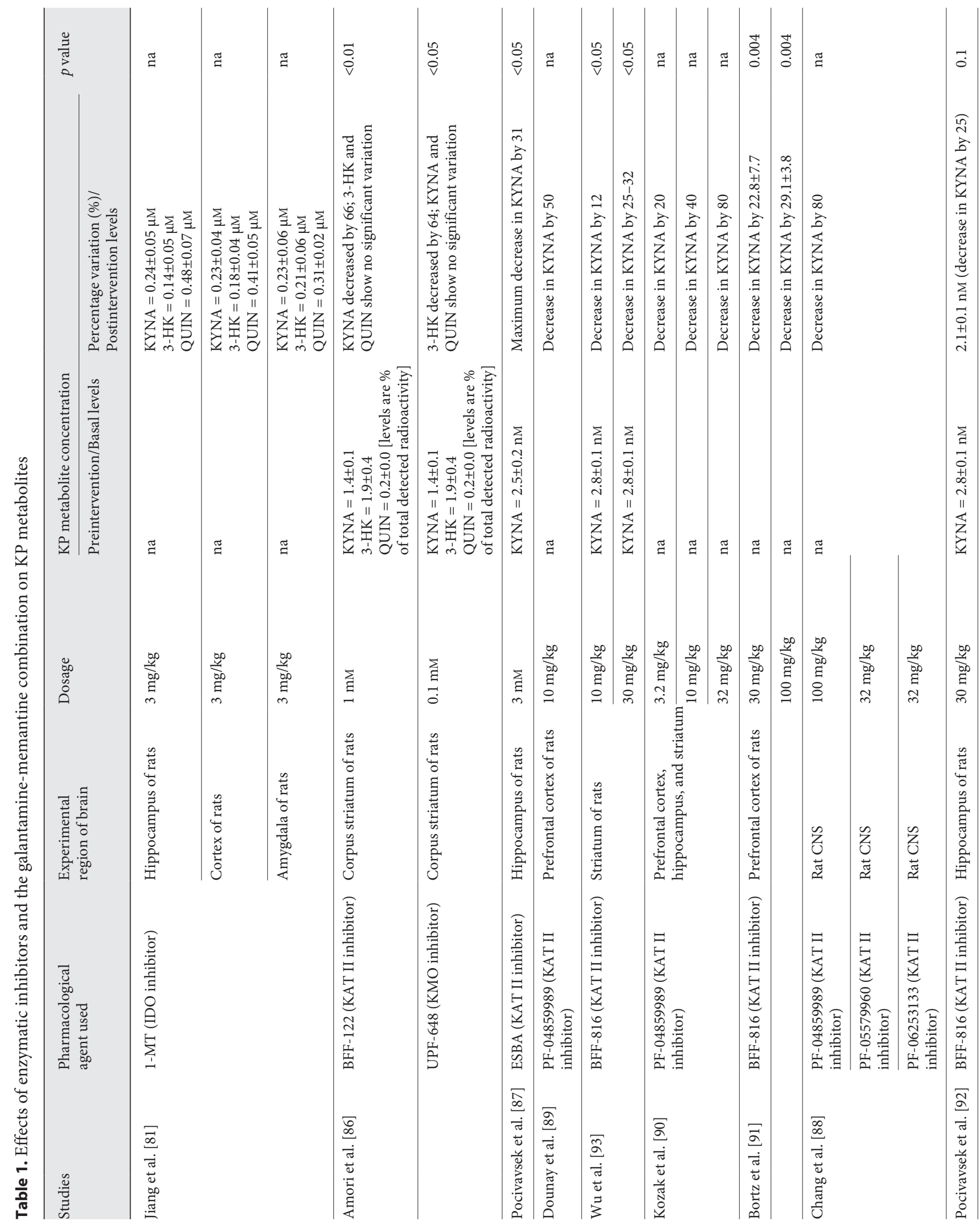




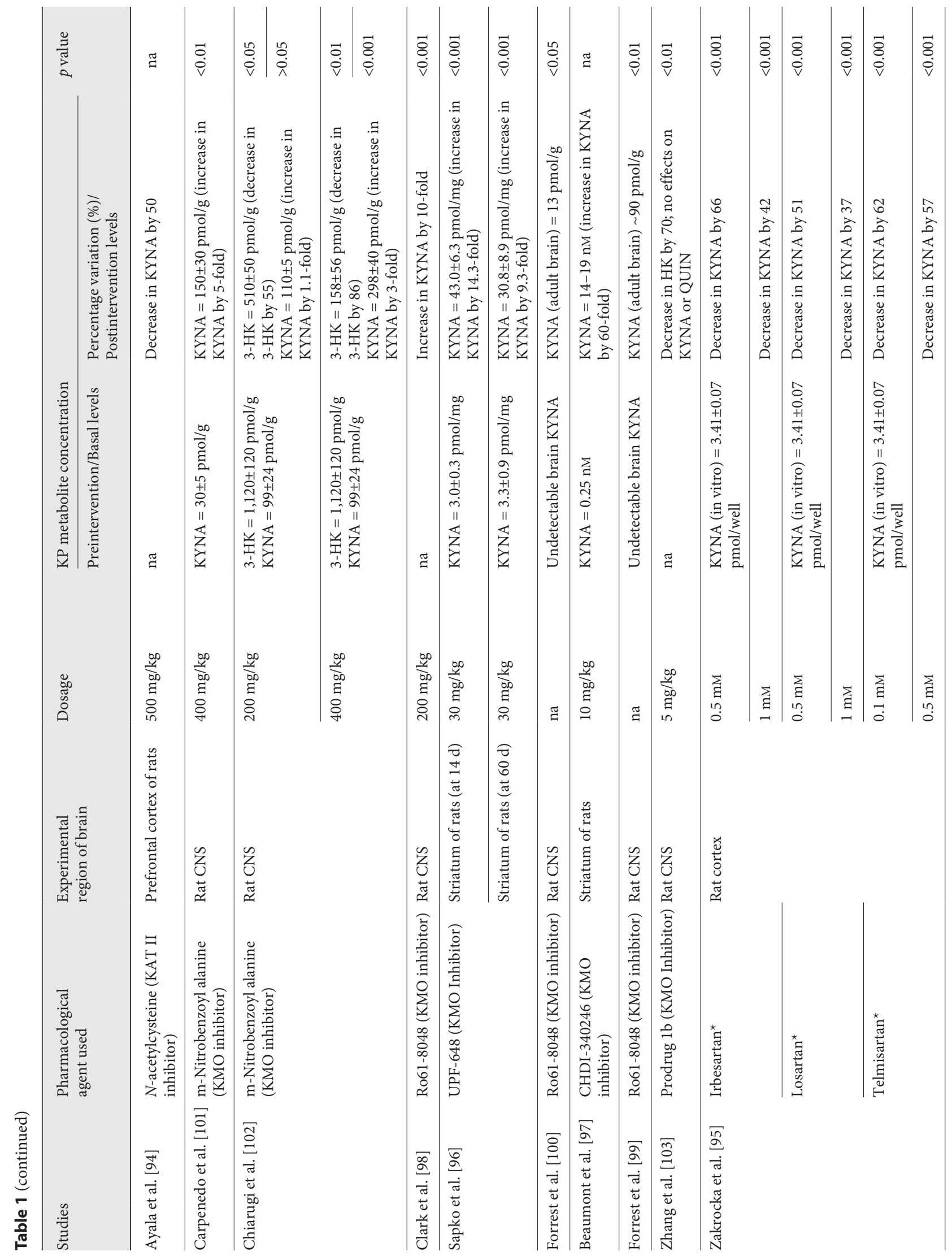




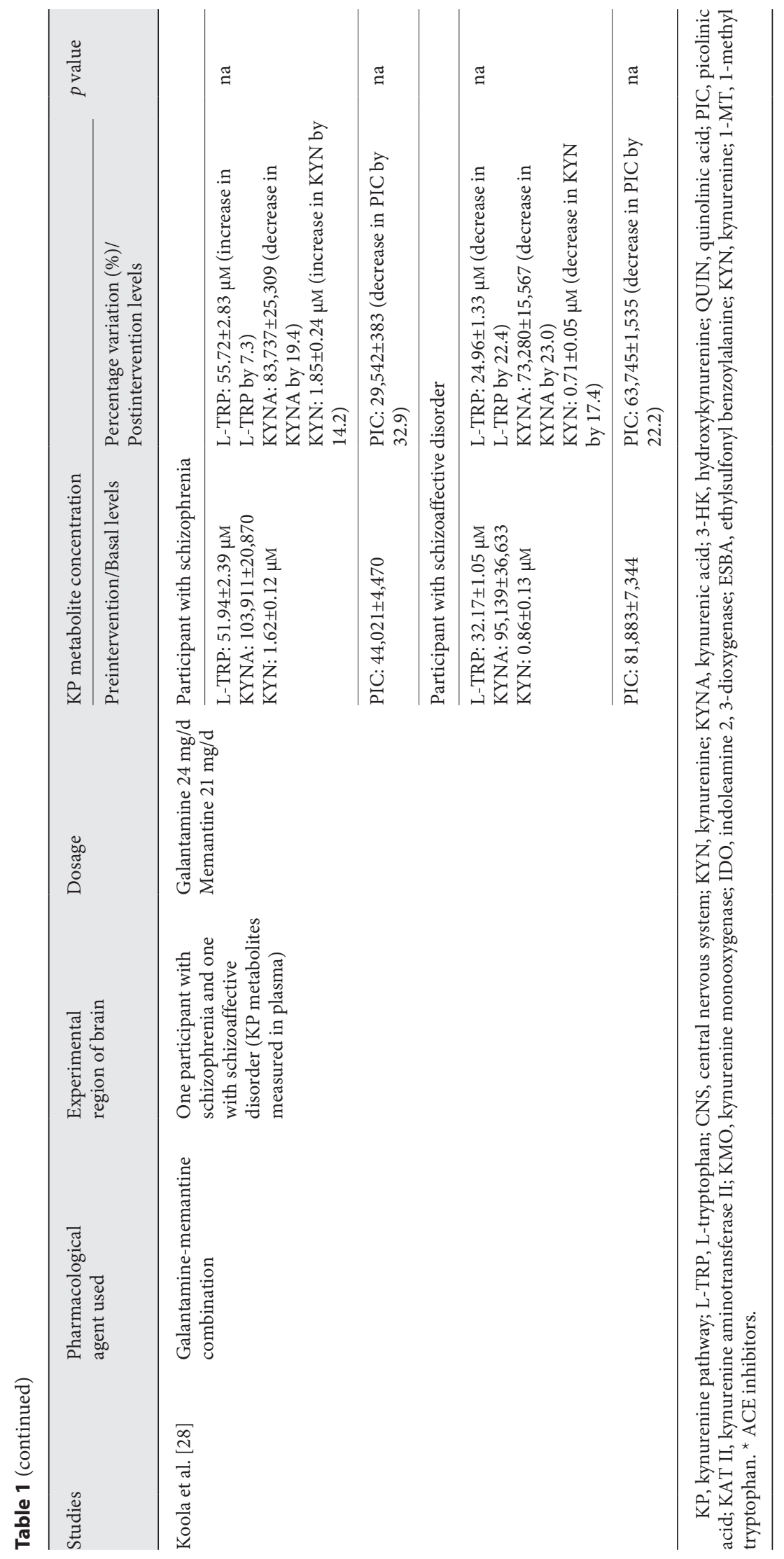


with the formation of KYN (in the liver, reproductive system, and brain) [74] except under conditions that involve extensive immune activation wherein IDO becomes relatively more active. TDO activity is largely boosted by means of adrenal glucocorticoids along with L-TRP [75]. On the contrary, IDO-1 activity is usually induced at the site of an inflammation by means of cytokines including interferon- $\gamma[76]$, the end result of which is an overall suppression of the body's defense system [77]. This immunomodulatory action of IDO- 1 has been shown to be utilized by certain body neoplasms and helps tumor cells evade the immune response [78]. Another isoform of IDO, IDO-2, is found in the hepatorenal tissues and the reproductive tract [79]. Similar to IDO-1, its expression is believed to be controlled via cytokines such as interferon- $\gamma[80]$.

In terms of KYN metabolites, a targeted inhibition of IDO-1 by 1-MT or 1-methyl tryptophan [81] plays a major role in increasing the levels of brain KYNA (Table 1), while simultaneously decreasing the concentrations of the neurotoxic 3-hydroxykynurenine (3-HK) and QUIN metabolites [22]. Among the 2 isomeric forms of 1-MT, 1-methyl-L-TRP and 1-methyl-D-TRP, the former has a significantly higher affinity for IDO-1 [82]. Due to a structural and functional similarity between the 2 IDO isozymes, IDO-2 activity is also downregulated by 1-MT [82]. In addition, limited evidence suggests that deletion of the TDO gene is associated with significantly increased levels of brain L-TRP as well as KYN, while 3-HK and KYNA levels increase only moderately [83].

\section{KAT II Inhibitors}

KAT regulates the conversion of KYN into KYNA. Although a number of isozymes (I-IV) have been isolated [21], the CNS mostly comprises KAT I and KAT II isoforms, with the latter being more active in KYNA formation [84]. KAT III and KAT IV along with the other 2 isoforms are capable of influencing the metabolism of a large number of amino acids, including different aromatic, neutral, and sulfur-containing amino acids [84, 85], which highlights the potentially overlapping biological role of KAT enzymes.

Among the candidates for KAT inhibition, only KAT II inhibitors have been studied in detail with the aid of animal models (Table 1). Quantitative data from these studies have shown an efficacious role of several KAT II inhibitors in decreasing the levels of KYNA in the rat brain. The KAT I inhibitor BFF-122 [86] has been shown to decrease de novo synthesis of KYNA by $66 \%$. It has been reported that (S)-4-(ethylsulfonyl) benzoylalanine [87] may decrease KYNA by $31 \%$ of baseline levels, while the drug PF-04859989 [88-90] may lower KYNA by $20-80 \%$. It is worthwhile to note that a lack of BBB permeability represents a major clinical hurdle when targeting this metabolic pathway. Until the advent of PF-04859989, the first known KAT II inhibitor to cross the BBB, efforts to develop KAT II inhibitors for human use were hindered because none of the other drugs could penetrate the BBB and thus had to be administered directly into the rat brain [89].

Another pharmacological agent, BFF-816, can reduce KYNA by $12-32 \%$ of initial concentrations [91-93]. Moreover, PF-05579960 and PF-06253133 can also decrease KYNA by $80 \%$ [88]. Interestingly, the glutathione precursor $\mathrm{N}$-acetylcysteine has also been effective in reducing KYNA by $50 \%$ of its baseline levels in the rat brain [94]. In addition, angiotensin II receptor blockers have also been demonstrated to block KAT II activity (Table 1), inducing a decrease in brain KYNA as high as $66 \%$ [95].

\section{KMO Inhibitors}

$\mathrm{KMO}$ is responsible for catalyzing the formation of 3 -HK. It is produced mainly by infiltrating macrophages and microglial cells [21]. KMO has also been studied as a potential target of several novel therapeutic agents. Animal data show that KMO inhibitors effectively reduce levels of the neurotoxic KP metabolite 3-HK and to a lesser extent QUIN, while also partially increasing KYNA concentration in the brain. As shown in Table 1, UPF-648 [86] has been associated with a decrease in brain 3-HK by $64 \%$. However, the QUIN and KYNA levels were not significantly altered in this particular study. Contrary to these findings, KYNA levels were remarkably elevated in another experimental study of UPF-648 [96], in which rat brain analysis showed an approximately 14 -fold increase in brain KYNA concentration.

Another novel pharmacological agent, CHDI-340246, has proven its efficacy in increasing KYNA levels in the rat brain by as much as 60 -fold. In addition, this KMO inhibitor also managed to increase 3-HK and QUIN levels in the rat striatum moderately [97]. Ro61-8048 is another experimental inhibitor of KMO that has been shown to substantially increase KYNA levels in the brain by more than 10-fold [98-100]. Another KMO inhibitor, meta-nitrobenzoyl alanine, has been studied widely [101, 102] and is associated with markedly elevated levels of KYNA in the rat brain (nearly 5 times more than the baseline). Similarly, meta-nitrobenzoyl alanine also leads to a reduction in brain levels of $3-\mathrm{HK}$ by approximately $86 \%$. A novel pharmacological agent, prodrug $1 \mathrm{~b}$, is capable of lowering the brain $3-\mathrm{HK}$ concentration by $70 \%$ [103]. 
Fig. 3. KYNA may not be an inhibitor of nicotinic receptors [44]. But, since KYNA blocks the glutamate-mediated effects of $a 7 \mathrm{nACh}$ receptors, it is possible that it may indirectly block the effects of $\alpha 7 \mathrm{nAChR}$. There are several ongoing studies that may shed light on this controversy. Meanwhile, galantamine and memantine can cross the $\mathrm{BBB}$ and target $\alpha 7$ nicotinic and NMDA receptors, respectively, thereby counteracting the effects of KYNA. KYNA, kynurenic acid; BBB, blood-brain barrier.

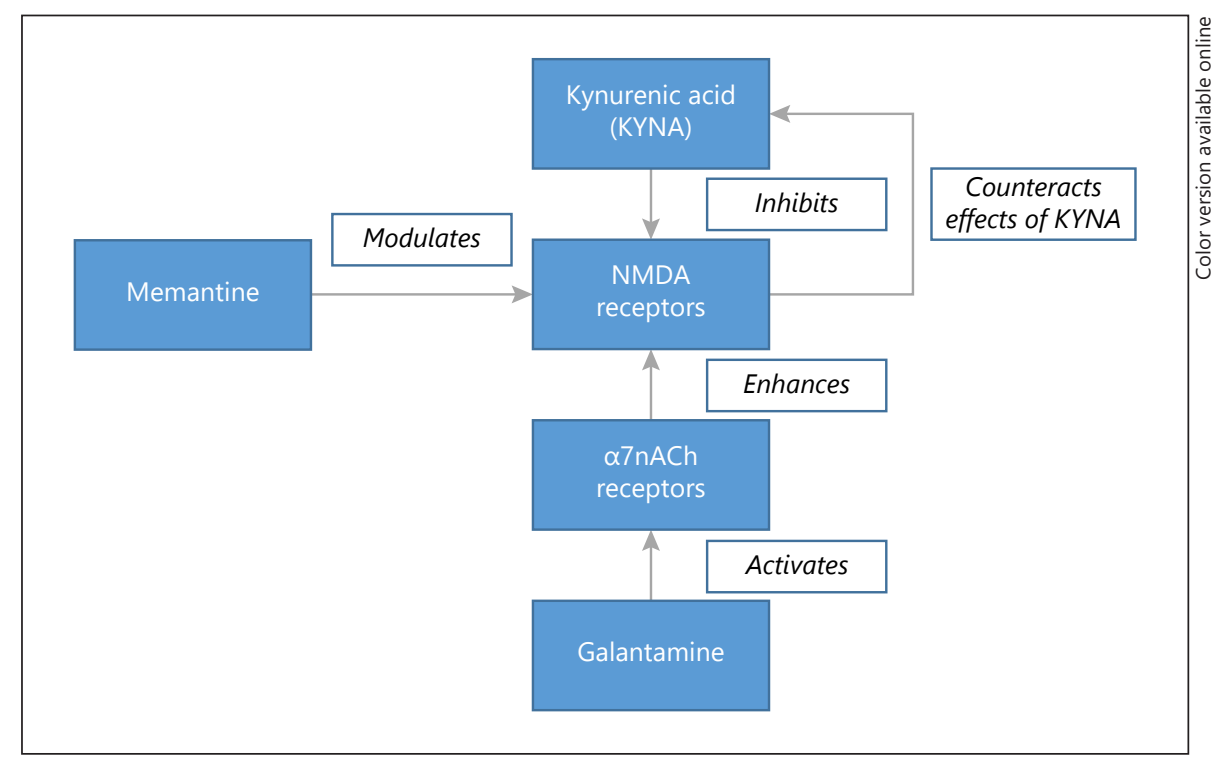

\section{Galantamine-Memantine Combination}

Only 2 pathophysiological mechanisms (cholinergic/ nicotinic-cholinergic and glutamatergic/NMDA) have been approved by the FDA for the treatment of cognitive dysfunction, and the galantamine-memantine combination is currently being used in $\mathrm{AD}$ for this purpose $[104,105]$. Memantine is known to antagonize glutamate activity at NMDA receptors $[20,26]$, a role also accomplished by KYNA [106-109], thereby attenuating the excitotoxic effects of QUIN [49]. KYNA is also known for its actions on cholinergic transmission in the brain [110-113], which can lead to the pathogenesis of AD [114], as shown in Fig. 2. It seems that KYNA does not act directly at $\alpha 7 \mathrm{nACh}$ receptors $[44,45]$ or antagonizes the action of acetylcholine [115], as further indicated in Fig. 3, 4. Galantamine acts by stimulating $\alpha 7 \mathrm{nAChR}$ [116] and other nicotinic receptors, including $\alpha 4 \beta 2$ receptors, which are the most abundant nicotinic receptors in the brain $[117,118]$. Stimulation of $\alpha 4 \beta 2$ $\mathrm{nAchR}$ is capable of inducing positive changes in both memory and attention as well as ameliorating deficits in motivation and reward processing, which are associated with a multitude of neurodegenerative diseases [119, 120]. An interactive effect of the galantamine-memantine combination in reducing oxidative stress and KP metabolites has also been documented extensively [121]. Moreover, these pharmacological agents may also enhance mismatch negativity [122], brain-derived neurotrophic factor [123], and synaptic density [124, 125].
The $a 7$ nicotinic-NMDA hypothesis has been recently published [61].

The potential of the galantamine-memantine combination was further demonstrated in a relatively small study (Table 1) that successfully estimated the effects of the 2 medications on the overall concentrations of various KP metabolites in plasma [28]. This is the only study of its kind involving human subjects. In this study, 2 participants with schizophrenia/schizoaffective disorder were treated with the galantamine-memantine combination, and plasma levels of L-TRP, KYNA, KYN, and PIC considerably improved as a result. At 6-week follow-up, the mean reduction of L-TRP, KYNA, KYN, and PIC was found to be $7.6,21.2,1.6$, and $27.5 \%$, respectively. Both subjects experienced some improvement in cognitive deficits as well as negative symptoms (suggestive of primary negative symptoms because at baseline psychosis, depression and extrapyramidal symptoms [factors associated with secondary negative symptoms] were none to minimal).

\section{Discussion}

Increasing evidence confirms the therapeutic efficacy of KP enzyme inhibitors and the galantamine-memantine combination in the alteration of concentrations of various KP metabolites. These significant findings may prove to be highly relevant to the efficacious management of schizophrenia [28, 126], AD [127-129], HD [130, 131],
Bai/Lovejoy/Guillemin/Kozak/Stone/ Koola 


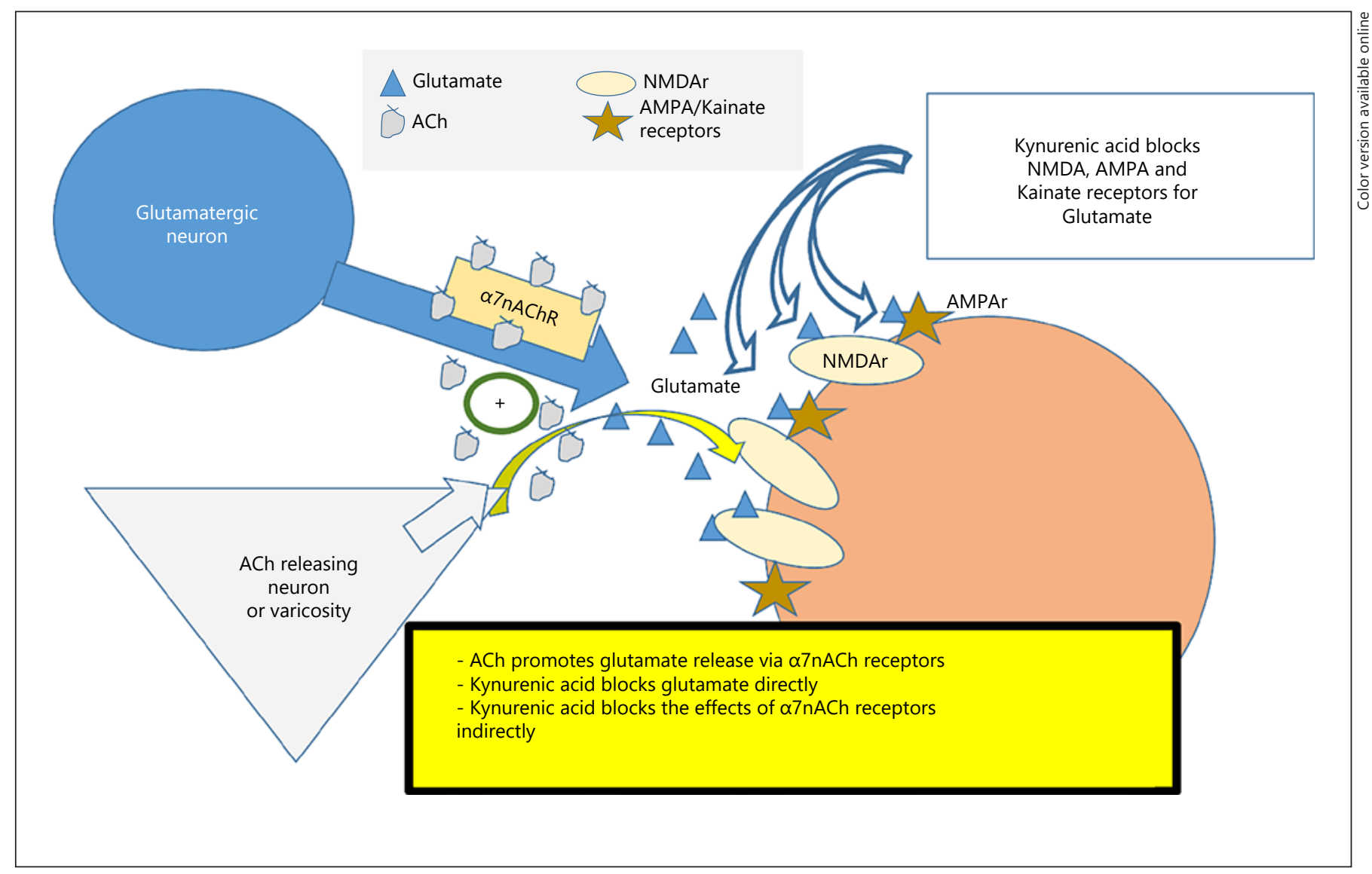

Fig. 4. Diagrammatic representation of a cholinergically modulated glutamatergic synapse to illustrate the usual site and mode of action of nicotinic receptors. ACh is released from cholinergic synaptic terminals or from cholinergic varicosities into an extracellular space with access to glutamatergic axon terminals. The normal action of ACh is to promote or facilitate the evoked release of glutamate onto its receptors, which will include pre- and postsynaptic receptors sensitive to NMDA, as well as receptors for AMPA and kainic acid. The dominant action of KYNA is to block all the glutamate receptors although with greatest potency at NMDA recep-

PD [132, 133], amyotrophic lateral sclerosis [134-136], bipolar disorder [137, 138], depression [139-141], autism spectrum disorder [142, 143], epilepsy [144-146], cognitive impairments secondary to traumatic brain injury $[147,148]$, electroconvulsive therapy [149], aging [150], chronic pain disorders [151], and other neuropsychiatric disorders [149, 152, 153].

KAT II inhibition and its impact on KYNA levels have been documented by several studies. An in-vivo animal study found that the KAT II inhibitor, PF-04859989, significantly reduced KYN-induced KYNA levels in the rat brain [154]. Another study with KAT II gene knockout mice showed markedly reduced hippocampal KYNA lev-

Galantamine-Memantine Combination and KP Enzyme Inhibitors for Neuropsychiatric Diseases tors since it blocks both the glutamate binding site and the co-agonist glycine binding site (not shown). This means that any facilitation of cholinergic activity, either by increasing ACh release or by allosteric modulators such as galantamine-enhancing Ach-receptor sensitivity, will indirectly promote glutamate release. They will therefore appear to overcome the blocking activity of KYNA even though they are acting through a different site from KYNA. Ach, acetylcholine; KYNA, kynurenic acid; AMPA, a-amino-3hydroxy-5-methyl-4-isoxazolepropionic acid.

els $(\sim 71 \% ; p<0.001)$ and an increased performance in cognitive tasks [155]. In another similar study, Yu et al. [156] reported a decrease in KYNA levels ranging from 48 to $60 \%$ following the deletion of KAT II gene in mice. Although no human trials have established the efficacy and safety profile of KAT II inhibitors, there is growing evidence that these pharmacological agents might play a decisive role in the management of neurocognitive disorders [157].

Targeted inhibition of IDO-1/TDO enzymes has been shown to reverse behavioral changes secondary to schizophrenia in rat models [158]. Coptisine, an essential component of traditional Chinese medicine, has 
proved to be an even more potent pharmacological inhibitor of IDO-1 compared to 1-MT and has been found to be useful in rat models of $\mathrm{AD}[159,160]$. It is noteworthy that TDO inhibitors have received less attention than IDO-1 inhibitors, particularly in the context of neurological disorders, reflecting that while TDO is found in the brain, it is primarily expressed in the liver. Recently, evidence regarding the experimental inhibition of IDO/TDO enzymes for immunomodulation in cancer therapy [161-163] has been increasing extensively. Still, there is a scarcity of clinical data of IDO/TDO inhibitors in relation to neurodegenerative disorders. $\mathrm{KMO}$ inhibitors have been thoroughly evaluated in animal studies. The systemic administration of JM-6 (a $\mathrm{KMO}$ inhibitor) has been associated with a significant elevation in KYNA levels in the rat brain [164]. Moreover, this was accompanied by improved memory and cognitive function in the rats. Studies involving mice with a knockout KMO gene (KMO-/-) have resulted in not only significantly increased KYNA $[165,166]$ but also grossly reduced 3 -HK levels in the mutant mice brain, along with declining cognitive and psychosocial functions [167]. However, brain QUIN concentrations did not decrease substantially in these cases [166]. Pellicciari and colleagues [168] also reported that although KMO inhibitors can potentially increase KYNA and KYN levels within the brain, there is no conclusive evidence to suggest that they also alter QUIN.

The efficacy of galantamine and memantine has been broadly elaborated by means of clinical studies. In a randomized controlled trial involving aged individuals with cognitive impairment, this drug combination was associated with a remarkable improvement in cognitive function compared to galantamine alone [169]. The galantamine-memantine combination has also proved to be more effective in AD than the donepezil-memantine combination [170]. Galantamine and memantine have proved to be efficacious in the management of $\mathrm{AD}$ due to their combined actions on a $7 \mathrm{nAChR}$ and NMDA receptors [149]. However, the synergistic activity of these 2 agents can also help avert the neurotoxic actions of QUIN by modulating KYNA. Keeping in mind their efficacy in the modulation of KP metabolites, it is possible to predict a therapeutic role of the galantaminememantine combination in schizophrenia [28] and other neuropsychiatric diseases $[149,171]$. Recent studies have indicated that galantamine and memantine can individually lead to significantly improved cognitive outcome in participants with schizophrenia $[172,173]$. The 2 pharmacological agents may be substantially benefi- cial in treating the cognitive impairments [174] as well as the negative symptoms observed in schizophrenia [175].

Based on current evidence, it can be concluded that KAT II inhibitors have the best efficacy in reducing the levels of brain KYNA in rats. Used in adequate doses, KYNA can be expected to decline by $80 \%$ of basal levels. In contrast, brain KYNA levels can be drastically elevated in rats treated with KMO inhibitors. However, galantamine-memantine treatment in human subjects can lead to a decrease in serum KYNA levels by approximately $30 \%$. This decline in plasma KYNA has been observed over a short duration of 6 weeks, which raises the possibility that much lower KYNA concentrations might be expected in patients over longer periods of time. Therefore, galantamine-memantine combined with KAT II inhibitors may have a potentially synergistic action in reducing KYNA levels in the brain [176].

Among KAT II inhibitors, KMO inhibitors, and the galantamine-memantine combination, only the latter is FDA approved and available for clinical use. A much broader clinical study comparing the relative efficacy of these drugs in the treatment of various neuropsychiatric disorders is thus warranted. The effects of these medications on modulating brain KYNA concentrations must be monitored precisely, which is possible through the careful utilization of PET tracers in subjects [177].

\section{Conclusion and Future Directions}

The KP enzyme inhibitors as well as galantamine-memantine combination, through their ability to modulate KP derivatives, are potentially suitable for neutralizing various impairments in neuropsychiatric disorders. In particular, the galantamine-memantine combination and KAT II inhibitors may exert a potent therapeutic effect by synergistically decreasing the KYNA concentrations in the CNS. Since KYNA is the "conductor of the orchestra" of the major pathophysiological mechanisms in CNS disorders, a possible future study comparing the effects of these 2 therapeutic options on the neosynthesis of KYNA [92] is essential to determine the most efficacious treatment for schizophrenia and other neuropsychiatric diseases.

\section{Conflict of Interest Statement}

The authors declare no conflicts of interest.
Bai/Lovejoy/Guillemin/Kozak/Stone/ Koola 


\section{Funding Sources}

This work was not funded.

\section{References}

1 Höglund E, Øverli Ø, Winberg S. Tryptophan metabolic pathways and brain serotonergic activity: a comparative review. Front. Endocrinol.. 2019;10:158.

2 Moroni F, Russi P, Lombardi G, Beni M, Carlà $V$. Presence of kynurenic acid in the mammalian brain. J Neurochem. 1988;51(1):17780.

3 Guillemin GJ, Cullen KM, Lim CK, Smythe GA, Garner B, Kapoor V, et al. Characterization of the kynurenine pathway in human neurons. J Neurosci. 2007;27(47):12884-92.

4 Chen Y, Guillemin GJ. Kynurenine pathway metabolites in humans: disease and healthy States. Int J Tryptophan Res. 2009;2:1-19.

5 Gellért L, Varga D, Ruszka M, Toldi J, Farkas T, Szatmári I, et al. Behavioural studies with a newly developed neuroprotective KYNA-amide. J Neural Transm. 2012;119(2):165-72

6 Urenjak J, Obrenovitch TP. Neuroprotective potency of kynurenic acid against excitotoxicity. Neuroreport. 2000;11(6):1341-4.

7 Ramos-Chávez LA, Lugo Huitrón R, González Esquivel D, Pineda B, Ríos C, Silva-Adaya D, et al. Relevance of alternative routes of kynurenic acid production in the brain. Oxid Med Cell Longevity. 2018;2018:1.

8 Török N, Tanaka M, Vécsei L. Searching for peripheral biomarkers in neurodegenerative diseases: the tryptophan-kynurenine metabolic pathway. Ijms. 2020;21(24):9338.

9 Kegel ME, Bhat M, Skogh E, Samuelsson M, Lundberg K, Dahl ML, et al. Imbalanced kynurenine pathway in schizophrenia. Int J Tryptophan Res. 2014;7:15-22.

10 Fazio F, Lionetto L, Curto M, Iacovelli L, Cavallari M, Zappulla $C$, et al. Xanthurenic acid activates mGlu2/3 metabotropic glutamate receptors and is a potential trait marker for schizophrenia. Sci Rep. 2015;5:17799.

11 Marx W, McGuinness AJ, Rocks T, Ruusunen A, Cleminson J, Walker AJ, et al. The kynurenine pathway in major depressive disorder, bipolar disorder, and schizophrenia: a meta-analysis of 101 studies. Molecular psychiatry. 2020. Epub ahead of print.

12 Meier TB, Drevets WC, Wurfel BE, Ford BN, Morris HM, Victor TA, et al. Relationship between neurotoxic kynurenine metabolites and reductions in right medial prefrontal cortical thickness in major depressive disorder. Brain Behav Immun. 2016;53:39-48.

13 Plangar I, Majlath Z, Vecsei L. Kynurenines in cognitive functions: their possible role in depression. Neuropsychopharmacol Hung. 2012;14(4):239-44.

14 Hunt C, Macedo E Cordeiro T, Suchting R, de Dios C, Cuellar Leal VA, Soares JC, et al. Effect of immune activation on the kynurenine

\section{Author Contributions}

Bai prepared the first draft. All authors edited with intellectual contribution and approved the final version of the manuscript. pathway and depression symptoms - A systematic review and meta-analysis. Neurosci Biobehav Rev. 2020;118:514-23.

15 Venkatesan D, Iyer M, Narayanasamy A, Siva K, Vellingiri B. Kynurenine pathway in Parkinson's disease-An update. eNeurologicalSci. 2020;21:100270.

16 Sorgdrager FJH, Vermeiren Y, Van Faassen $M$, van der Ley C, Nollen EAA, Kema IP, et al. Age- and disease-specific changes of the kynurenine pathway in Parkinson's and Alzheimer's disease. J Neurochem. 2019;151(5):65668.

17 Sellgren CM, Gracias J, Jungholm O, Perlis RH, Engberg G, Schwieler L, et al. Peripheral and central levels of kynurenic acid in bipolar disorder subjects and healthy controls. Transl Psychiatry. 2019;9(1):37.

18 Tanaka M, Toldi J, Vécsei L. Exploring the etiological links behind neurodegenerative diseases: inflammatory cytokines and bioactive kynurenines. Internat J Mol Sci. 2020; 21(7):2431

19 Aeinehband S, Brenner P, Ståhl S, Bhat M, Fidock MD, Khademi M, et al. Cerebrospinal fluid kynurenines in multiple sclerosis; relation to disease course and neurocognitive symptoms. Brain Behav Immun. 2016;51:4755.

20 Tanaka M, Bohár Z, Vécsei L. Are kynurenines accomplices or principal villains in dementia? Maintenance of kynurenine metabolism. Molecules. 2020;25(3):564.

21 Jacobs KR, Castellano-Gonzalez G, Guillemin GJ, Lovejoy DB. Major developments in the design of inhibitors along the kynurenine pathway. Curr Med Chem. 2017;24(23): 2471-95.

22 Mazarei G, Leavitt BR. Indoleamine 2,3 dioxygenase as a potential therapeutic target in Huntington's disease. J Huntingtons Dis. 2015;4(2):109-18.

23 Stone TW. Inhibitors of the kynurenine pathway. Eur J Med Chem. 2000;35(2):179-86.

24 Koola MM. Galantamine-memantine combination in the treatment of Alzheimer's disease and beyond. Psychiatry Res. 2020;293: 113409.

25 Lieberman JA, Papadakis K, Csernansky J, Litman R, Volavka J, Jia XD, et al. A randomized, placebo-controlled study of memantine as adjunctive treatment in patients with schizophrenia. Neuropsychopharmacology. 2009;34(5):1322-9.

26 Conway ME. Alzheimer's disease: targeting the glutamatergic system. Biogerontology. 2020;21(3):257-74

27 Wu HM, Tzeng NS, Qian L, Wei SJ, Hu X, Chen SH, et al. Novel neuroprotective mecha- nisms of memantine: increase in neurotrophic factor release from astroglia and anti-inflammation by preventing microglial activation. Neuropsychopharmacology. 2009; 34(10):2344-57.

28 Koola MM, Sklar J, Davis W, Nikiforuk A, Meissen JK, Sawant-Basak A, et al. Kynurenine pathway in schizophrenia: galantaminememantine combination for cognitive impairments. Schizophr Res. 2018;193:459-60.

29 Dounay AB, Tuttle JB, Verhoest PR. Challenges and opportunities in the discovery of new therapeutics targeting the kynurenine pathway. J Med Chem. 2015;58(22):8762-82.

30 Jospeh MH, Baker HF, Crow TJ, Riley GJ, Risby D. Brain tryptophan metabolism in schizophrenia: a post mortem study of metabolites of the serotonin and kynurenine pathways in schizophrenic and control subjects. Psychopharmacology. 1979;62(3):279-85.

31 Faurbye A, Pind K. Investigations on the tryptophane metabolism (via kynurenine) in schizophrenic patents. Acta Psychiatr Scand. 1964;40(3):244-8.

32 Schwarcz R, Rassoulpour A, Wu HQ, Medoff D, Tamminga CA, Roberts RC. Increased cortical kynurenate content in schizophrenia. Biol Psychiatry. 2001;50(7):521-30.

33 Erhardt S, Blennow K, Nordin C, Skogh E, Lindström LH, Engberg G. Kynurenic acid levels are elevated in the cerebrospinal fluid of patients with schizophrenia. Neurosci Lett. 2001;313(1-2):96-8.

34 Coyle JT. NMDA receptor and schizophrenia: a brief history. Schizophr Bull. 2012;38(5): 920-6.

35 Małgorzata P, Paweł K, Iwona ML, Brzostek T, Andrzej P. Glutamatergic dysregulation in mood disorders: opportunities for the discovery of novel drug targets. Expert Opin Ther Targets. 2020;24(12):1187-209.

36 Erhardt S, Schwieler L, Nilsson L, Linderholm $\mathrm{K}$, Engberg G. The kynurenic acid hypothesis of schizophrenia. Physiol Behav. 2007;92(12):203-9.

37 Jentsch JD, Roth RH. The neuropsychopharmacology of phencyclidine: from NMDA receptor hypofunction to the dopamine hypothesis of schizophrenia. Neuropsychopharmacology. 1999;20(3):201-25.

$38 \mathrm{Wu}$ HQ, Rassoulpour A, Schwarcz R. Kynurenic acid leads, dopamine follows: a new case of volume transmission in the brain? J Neural Transm. 2007;114(1):33-41

39 Okuno A, Fukuwatari T, Shibata K. High tryptophan diet reduces extracellular dopamine release via kynurenic acid production in rat striatum. J Neurochem. 2011;118(5):796805 . 
40 Yoon JH, Maddock RJ, DongBo Cui E, Minzenberg MJ, Niendam TA, Lesh T, et al. Reduced in vivo visual cortex GABA in schizophrenia, a replication in a recent onset sample. Schizophr Res. 2020;215:217-22.

41 Beggiato S, Tanganelli S, Fuxe K, Antonelli T, Schwarcz R, Ferraro L. Endogenous kynurenic acid regulates extracellular GABA levels in the rat prefrontal cortex. Neuropharmacology. 2014;82:11-8.

42 Hilmas C, Pereira EF, Alkondon M, Rassoulpour A, Schwarcz R, Albuquerque EX. The brain metabolite kynurenic acid inhibits alpha7 nicotinic receptor activity and increases non-alpha7 nicotinic receptor expression: physiopathological implications. J Neurosci. 2001;21(19):7463-73.

43 Obara-Michlewska M, Tuszyńska P, Albrecht J. Ammonia upregulates kynurenine aminotransferase II mRNA expression in rat brain: a role for astrocytic NMDA receptors?. Metab Brain Dis. 2013;28(2):161-5.

44 Stone TW. Does kynurenic acid act on nicotinic receptors? An assessment of the evidence. J Neurochem. 2020;152(6):627-49.

45 Dobelis P, Staley KJ, Cooper DC. Lack of modulation of nicotinic acetylcholine alpha-7 receptor currents by kynurenic acid in adult hippocampal interneurons. PloS one. 2012; 7(7):e41108.

$46 \mathrm{Wu}$ HQ, Salituro FG, Schwarcz R. Enzymecatalyzed production of the neuroprotective NMDA receptor antagonist 7-chlorokynurenic acid in the rat brain in vivo. Eur J Pharmacol. 1997;319(1):13-20.

47 Németh H, Toldi J, Vécsei L. Kynurenines, Parkinson's disease and other neurodegenerative disorders: preclinical and clinical studies. J Neural Transm Suppl. 2006;70(70):285304.

48 Lim CK, Fernández-Gomez FJ, Braidy N, Estrada C, Costa C, Costa S, et al. Involvement of the kynurenine pathway in the pathogenesis of Parkinson's disease. Prog Neurobiol. 2017;155:76-95.

49 Zádori D, Nyiri G, Szonyi A, Szatmári I, Fülöp F, Toldi J, et al. Neuroprotective effects of a novel kynurenic acid analogue in a transgenic mouse model of Huntington's disease. J Neural Transm. 2011;118(6):865-75

50 Gulaj E, Pawlak K, Bien B, Pawlak D. Kynurenine and its metabolites in Alzheimer's disease patients. Adv Med Sci. 2010;55(2): 204-11.

51 Lugo-Huitrón R, Blanco-Ayala T, Ugalde-Muñiz P, Carrillo-Mora P, Pedraza-Chaverrí J, Silva-Adaya $\mathrm{D}$, et al. On the antioxidant properties of kynurenic acid: free radical scavenging activity and inhibition of oxidative stress. Neurotoxicol Teratol. 2011;33(5):538-47.

52 DiNatale BC, Murray IA, Schroeder JC, Flaveny CA, Lahoti TS, Laurenzana EM, et al Kynurenic acid is a potent endogenous aryl hydrocarbon receptor ligand that synergistically induces interleukin-6 in the presence of inflammatory signaling. Toxicol Sci. 2010; 115(1):89-97.
53 Mándi Y, Vécsei L. The kynurenine system and immunoregulation. J Neural Transm. 2012;119(2): 197-209

54 Müller N, Myint AM, Krause D, Weidinger E Schwarz MJ. Anti-inflammatory treatment in schizophrenia. Prog Neuropsychopharmacol Biol Psychiatry. 2013;42:146-53.

55 Wonodi I, Schwarcz R. Cortical kynurenine pathway metabolism: a novel target for cognitive enhancement in schizophrenia. Schizophr Bull. 2010;36(2):211-8.

56 Pocivavsek A, Notarangelo FM, Wu H-Q, Bruno JP, Schwarcz R. Astrocytes as pharmacological targets in the treatment of schizophrenia: focus on kynurenic acid. In: Modeling the psychopathological dimensions of schizophrenia: from molecules to behavior. San Diego, CA, USA: Elsevier Academic Press; 2016. p. 423-43.

57 Blanco Ayala T, Lugo Huitrón R, Carmona Aparicio L, Ramírez Ortega D, González Esquivel D, Pedraza Chaverrí J, et al. Alternative kynurenic acid synthesis routes studied in the rat cerebellum. Front Cell Neurosci. 2015;9: 178.

58 Coyle JT, Puttfarcken P. Oxidative stress, glutamate, and neurodegenerative disorders. Science. 1993;262(5134):689-95.

59 Pedraz-Petrozzi B, Elyamany O, Rummel C, Mulert C. Effects of inflammation on the kynurenine pathway in schizophrenia - a systematic review. J Neuroinflammation. 2020; 17(1):56.

60 Tanaka M, Vécsei L. Monitoring the redox status in multiple sclerosis. Biomedicines. 2020;8(10):406.

61 Koola MM. Alpha7 nicotinic-NMDA hypothesis in the treatment of schizophrenia and beyond. Human Psychopharmacol Clin Exp. 2021;36:1-16.

62 Belladonna ML, Grohmann U, Guidetti P, Volpi C, Bianchi R, Fioretti MC, et al. Kynurenine pathway enzymes in dendritic cells initiate tolerogenesis in the absence of functional IDO. J Immunol. 2006;177(1): $130-7$

63 Orabona C, Puccetti P, Vacca C, Bicciato S, Luchini A, Fallarino F, et al. Toward the identification of a tolerogenic signature in IDOcompetent dendritic cells. Blood. 2006; 107(7):2846-54.

64 Stone TW, Stoy N, Darlington LG. An expanding range of targets for kynurenine metabolites of tryptophan. Trends Pharmacol Sci. 2013;34(2):136-43.

65 Walczak K, Wnorowski A, Turski WA, Plech T. Kynurenic acid and cancer: facts and controversies. Cell Mol Life Sci. 2020;77(8):153150.

66 Alexander KS, Wu HQ, Schwarcz R, Bruno JP. Acute elevations of brain kynurenic acid impair cognitive flexibility: normalization by the alpha7 positive modulator galantamine. Psychopharmacology. 2012;220(3): $627-37$

67 Stone TW, Darlington LG. The kynurenine pathway as a therapeutic target in cognitive and neurodegenerative disorders. Br J Pharmacol. 2013;169(6):1211-27.

68 Wonodi I, Schwarcz R. Cortical kynurenine pathway metabolism: a novel target for cognitive enhancement in schizophrenia. Schizophr Bull. 2010;36(2):211-8.

69 Solvang S-EH, Nordrehaug JE, Tell GS Nygård O, McCann A, Ueland PM, et al. The kynurenine pathway and cognitive performance in community-dwelling older adults. The Hordaland Health Study. Brain Behav Immun. 2019;75:155-62.

70 Holmberg D, Franzén-Röhl E, Idro R, Opoka RO, Bangirana P, Sellgren CM, et al. Cerebrospinal fluid kynurenine and kynurenic acid concentrations are associated with coma duration and long-term neurocognitive impairment in Ugandan children with cerebral malaria. Malar J. 2017;16(1):303.

71 Ramos-Chávez LA, Roldán-Roldán G, García-Juárez B, González-Esquivel D, Pérez de la Cruz G, Pineda B, et al. Low serum tryptophan levels as an indicator of global cognitive performance in nondemented women over 50 years of age. Oxid Med Cell Longevity. 2018; 2018:8604718.

72 de Bie J, Lim CK, Guillemin GJ. Kynurenines, gender and neuroinflammation; showcase schizophrenia. Neurotox Res. 2016;30(3): 285-94.

73 Gos T, Myint AM, Schiltz K, Meyer-Lotz G, Dobrowolny H, Busse S, et al. Reduced microglial immunoreactivity for endogenous NMDA receptor agonist quinolinic acid in the hippocampus of schizophrenia patients. Brain Behav Immun. 2014;41:59-64.

$74 \mathrm{Yu}$ CP, Pan ZZ, Luo DY. TDO as a therapeutic target in brain diseases. Metab Brain Dis. 2016;31(4):737-47.

75 Badawy AA. Kynurenine pathway of tryptophan metabolism: regulatory and functional aspects. Int J Tryptophan Res. 2017;10: 1178646917691938.

76 Pallotta MT, Orabona C, Volpi C, Vacca C, Belladonna ML, Bianchi R, et al. Indoleamine 2,3-dioxygenase is a signaling protein in longterm tolerance by dendritic cells. Nat Immunol. 2011;12(9):870-8.

77 Yentz S, Smith D. Indoleamine 2,3-dioxygenase (IDO) inhibition as a strategy to augment cancer immunotherapy. BioDrugs. 2018; 32(4):311-7.

78 Yeung AW, Terentis AC, King NJ, Thomas SR. Role of indoleamine 2,3-dioxygenase in health and disease. Clin Sci. 2015;129(7):60172

79 Weng T, Qiu X, Wang J, Li Z, Bian J. Recent discovery of indoleamine-2,3-dioxygenase 1 inhibitors targeting cancer immunotherapy. Eur J Med Chem. 2018;143:656-69.

80 Löb S, Königsrainer A, Zieker D, Brücher BL, Rammensee HG, Opelz G, et al. IDO1 and IDO2 are expressed in human tumors: levobut not dextro-1-methyl tryptophan inhibits tryptophan catabolism. Cancer immunology, immunotherapy. Cancer Immunol Immunother. 2009;58(1):153-7. 
81 Jiang X, Lin Q, Xu L, Chen Z, Yan Q, Chen L, et al. Indoleamine-2,3-dioxygenase mediates emotional deficits by the kynurenine/tryptophan pathway in the ethanol addiction/withdrawal mouse model. Front Cell Neurosci. 2020;14:11.

82 Austin CJ, Mailu BM, Maghzal GJ, SanchezPerez A, Rahlfs S, Zocher K, et al. Biochemical characteristics and inhibitor selectivity of mouse indoleamine 2,3-dioxygenase-2. Amino Acids. 2010;39(2):565-78.

83 Larkin PB, Sathyasaikumar KV, Notarangelo FM, Funakoshi $\mathrm{H}$, Nakamura $\mathrm{T}$, Schwarcz R, et al. Tryptophan 2,3-dioxygenase and indoleamine 2,3-dioxygenase 1 make separate, tissue-specific contributions to basal and inflammation-induced kynurenine pathway metabolism in mice. Biochim Biophys Acta. 2016;1860(11 Pt A): 2345-54.

84 Han Q, Cai T, Tagle DA, Li J. Structure, expression, and function of kynurenine aminotransferases in human and rodent brains. Cell Mol Life Sci. 2010;67(3):353-68.

85 Yu P, Li Z, Zhang L, Tagle DA, Cai T. Characterization of kynurenine aminotransferase III, a novel member of a phylogenetically conserved KAT family. Gene. 2006;365:1118.

86 Amori L, Guidetti P, Pellicciari R, Kajii Y, Schwarcz R. On the relationship between the two branches of the kynurenine pathway in the rat brain in vivo. J Neurochem. 2009; 109(2):316-25.

87 Pocivavsek A, Wu HQ, Potter MC, Elmer GI, Pellicciari R, Schwarcz R. Fluctuations in endogenous kynurenic acid control hippocampal glutamate and memory. Neuropsychopharmacology. 2011;36(11):2357-67.

88 Chang C, Fonseca KR, Li C, Horner W, Zawadzke LE, Salafia MA, et al. Quantitative translational analysis of brain kynurenic acid modulation via irreversible kynurenine aminotransferase II Inhibition. Mol Pharmacol. 2018;94(2):823-33.

89 Dounay AB, Anderson M, Bechle BM, Campbell BM, Claffey MM, Evdokimov A, et al. Discovery of brain-penetrant, irreversible kynurenine aminotransferase II inhibitors for schizophrenia. ACS Med Chem Lett. 2012; 3(3):187-92.

90 Kozak R, Campbell BM, Strick CA, Horner W, Hoffmann WE, Kiss T, et al. Reduction of brain kynurenic acid improves cognitive function. J Neurosci. 2014;34(32):10592-602.

91 Bortz DM, Wu HQ, Schwarcz R, Bruno JP. Oral administration of a specific kynurenic acid synthesis (KAT II) inhibitor attenuates evoked glutamate release in rat prefrontal cortex. Neuropharmacology. 2017;121:6978.

92 Pocivavsek A, Elmer GI, Schwarcz R. Inhibition of kynurenine aminotransferase II attenuates hippocampus-dependent memory deficit in adult rats treated prenatally with kynurenine. Hippocampus. 2019;29(2):737.

Galantamine-Memantine Combination and KP Enzyme Inhibitors for Neuropsychiatric Diseases
93 Wu HQ, Okuyama M, Kajii Y, Pocivavsek A, Bruno JP, Schwarcz R. Targeting kynurenine aminotransferase II in psychiatric diseases: promising effects of an orally active enzyme inhibitor. Schizophr Bull. 2014; 40(Suppl 2):S152-8.

94 Ayala TB, Sathyasaikumar KV, Uys JD, Pérezde-la-Cruz V, Pidugu LS, Schwarcz R. N-acetylcysteine inhibits kynurenine aminotransferase II. Neuroscience. 2020;444:160-9.

95 Zakrocka I, Targowska-Duda KM, Wnorowski A, Kocki T, Jóźwiak K, Turski WA. Angiotensin II type 1 receptor blockers inhibit KAT II activity in the brain-its possible clinical applications. Neurotox Res. 2017;32(4):639-48.

96 Sapko MT, Guidetti P, Yu P, Tagle DA, Pellicciari R, Schwarcz R. Endogenous kynurenate controls the vulnerability of striatal neurons to quinolinate: implications for Huntington's disease. Exp Neurol. 2006; 197(1):31-40.

97 Beaumont V, Mrzljak L, Dijkman U, Freije R, Heins M, Rassoulpour A, et al. The novel KMO inhibitor CHDI-340246 leads to a restoration of electrophysiological alterations in mouse models of Huntington's disease. Exp Neurol. 2016;282:99-118.

98 Clark CJ, Mackay GM, Smythe GA, Bustamante S, Stone TW, Phillips RS. Prolonged survival of a murine model of cerebral malaria by kynurenine pathway inhibition. Infect Immun. 2005;73(8):5249-51.:

99 Forrest CM, Kennedy PG, Rodgers J, Dalton RN, Turner C, Darlington LG, et al. Kynurenine pathway metabolism following prenatal KMO inhibition and in Mecp2(+/-) mice, using liquid chromatography-tandem mass spectrometry. Neurochem Internat. 2016;100:110-9.

100 Forrest CM, Khalil OS, Pisar M, Darlington LG, Stone TW. Prenatal inhibition of the tryptophan-kynurenine pathway alters synaptic plasticity and protein expression in the rat hippocampus. Brain Res. 2013;1504:1-15.

101 Carpenedo R, Chiarugi A, Russi P, Lombardi G, Carlà V, Pellicciari R, et al. Inhibitors of kynurenine hydroxylase and kynureninase increase cerebral formation of kynurenate and have sedative and anticonvulsant activities. Neuroscience. 1994;61(2):237-43.

102 Chiarugi A, Carpenedo R, Moroni F. Kynurenine disposition in blood and brain of mice: effects of selective inhibitors of kynurenine hydroxylase and of kynureninase. J Neurochem. 1996;67(2):692-8.

103 Zhang S, Sakuma M, Deora GS, Levy CW, Klausing A, Breda C, et al. A brain-permeable inhibitor of the neurodegenerative disease target kynurenine 3-monooxygenase prevents accumulation of neurotoxic metabolites. Commun Biol. 2019;2:271.

104 Grossberg GT, Edwards KR, Zhao Q. Rationale for combination therapy with galantamine and memantine in Alzheimer's disease. J Clin Pharmacol. 2006;46(7 Suppl 1): $17 s-26 s$.
105 Geerts H, Grossberg GT. Pharmacology of acetylcholinesterase inhibitors and $\mathrm{N}$-methyl-D-aspartate receptors for combination therapy in the treatment of Alzheimer's disease. J Clin Pharmacol. 2006;46(7 Suppl 1): $8 s-16 s$.

106 Alkondon M, Pereira EF, Yu P, Arruda EZ Almeida LE, Guidetti P, et al. Targeted deletion of the kynurenine aminotransferase ii gene reveals a critical role of endogenous kynurenic acid in the regulation of synaptic transmission via alpha7 nicotinic receptors in the hippocampus. J Neurosci. 2004; 24(19):4635-48.

107 Yoshida J, Shigemura A, Ogino Y, Denbow DM, Furuse M. Two receptors are involved in the central functions of kynurenic acid under an acute stress in neonatal chicks. Neuroscience. 2013;248:194-200.

108 Alkondon M, Pereira EF, Albuquerque EX. Endogenous activation of nAChRs and NMDA receptors contributes to the excitability of CA1 stratum radiatum interneurons in rat hippocampal slices: effects of kynurenic acid. Biochem Pharmacol. 2011, 82(8):842-51

109 Majláth Z, Török N, Toldi J, Vécsei L. Memantine and kynurenic acid: current neuropharmacological aspects. Curr Neuropharmacol. 2016;14(2):200-9.

110 Lopes C, Pereira EF, Wu HQ, Purushottamachar P, Njar V, Schwarcz R, et al. Competitive antagonism between the nicotinic allosteric potentiating ligand galantamine and kynurenic acid at alpha7* nicotinic receptors. Pharmacol Exp Ther. 2007;322(1):48-58.

111 Banerjee J, Alkondon M, Albuquerque EX. Kynurenic acid inhibits glutamatergic transmission to CA1 pyramidal neurons via a7 nAChR-dependent and -independent mechanisms. Biochem Pharmacol. 2012; 84(8):1078-87.

112 Alkondon M, Pereira EF, Eisenberg HM Kajii Y, Schwarcz R, Albuquerque EX. Age dependency of inhibition of alpha7 nicotinic receptors and tonically active $\mathrm{N}$-methyl-Daspartate receptors by endogenously produced kynurenic acid in the brain. J Pharmacol Exp Ther. 2011;337(3):572-82.

113 Stone TW. Kynurenic acid blocks nicotinic synaptic transmission to hippocampal interneurons in young rats. Eur J Neurosci. 2007; 25(9):2656-65.

114 Mesulam M. The cholinergic lesion of Alzheimer's disease: pivotal factor or side show?. Learn Mem. 2004;11(1):43-9.

115 Perkins MN, Stone TW. An iontophoretic investigation of the actions of convulsant kynurenines and their interaction with the endogenous excitant quinolinic acid. Brain Res. 1982;247(1):184-7.

116 Alexander KS, Pocivavsek A, Wu HQ, Pershing ML, Schwarcz R, Bruno JP. Early developmental elevations of brain kynurenic acid impair cognitive flexibility in adults: reversal with galantamine. Neuroscience. 2013;238:19-28. 
117 Mazzaferro S, Bermudez I, Sine SM. $\alpha 4 \beta 2$ nicotinic acetylcholine receptors: relationships between subunit stoichiometry and function at the single channel level. J Biol Chem. 2017;292(7):2729-40.

118 Nashmi R, Dickinson ME, McKinney S, Jareb M, Labarca C, Fraser SE, et al. Assembly of alpha4beta2 nicotinic acetylcholine receptors assessed with functional fluorescently labeled subunits: effects of localization, trafficking, and nicotine-induced upregulation in clonal mammalian cells and in cultured midbrain neurons. J Neurosci. 2003; 23(37):11554-67.

119 Bain EE, Robieson W, Pritchett Y, Garimella T, Abi-Saab W, Apostol G, et al. A randomized, double-blind, placebo-controlled phase 2 study of $\alpha 4 \beta 2$ agonist ABT-894 in adults with ADHD. Neuropsychopharmacology. 2013;38(3):405-13.

120 Rezvani AH, Levin ED. Nicotine-antipsychotic drug interactions and attentional performance in female rats. Eur J Pharmacol. 2004;486(2):175-82.

121 Koola MM, Praharaj SK, Pillai A. Galantamine-memantine combination as an antioxidant treatment for schizophrenia. Curr Behav Neurosci Rep. 2019;6(2):37-50.

122 Hamilton HK, D'Souza DC, Ford JM, Roach BJ, Kort NS, Ahn KH, et al. Interactive effects of an N-methyl-d-aspartate receptor antagonist and a nicotinic acetylcholine receptor agonist on mismatch negativity: Implications for schizophrenia. Schizophr Res. 2018;191:87-94.

123 Massey KA, Zago WM, Berg DK. BDNF upregulates alpha7 nicotinic acetylcholine receptor levels on subpopulations of hippocampal interneurons. Mol Cell Neurosci. 2006;33(4):381-8.

124 Lin H, Hsu FC, Baumann BH, Coulter DA, Lynch DR. Cortical synaptic NMDA receptor deficits in a7 nicotinic acetylcholine receptor gene deletion models: implications for neuropsychiatric diseases. Neurobiology of disease. 2014;63:129-40.

125 Scarr E, Gibbons AS, Neo J, Udawela M, Dean B. Cholinergic connectivity: it's implications for psychiatric disorders. Front Cell Neurosci. 2013;7:55.[

126 Müller N, Myint AM, Schwarz MJ. Kynurenine pathway in schizophrenia: pathophysiological and therapeutic aspects. Curr Pharm Des. 2011;17(2):130-6.

127 Giil LM, Midttun Ø, Refsum H, Ulvik A, Advani $\mathrm{R}$, Smith $\mathrm{AD}$, et al. Kynurenine pathway metabolites in Alzheimer's disease. J Alzheimers Dis. 2017;60(2):495-504.

128 Zádori D, Veres G, Szalárdy L, Klivényi P, Vécsei L. Alzheimer's disease: recent concepts on the relation of mitochondrial disturbances, excitotoxicity, neuroinflammation, and kynurenines. Jad. 2018;62(2):52347.

129 Plangár I, Zádori D, Klivényi P, Toldi J, Vécsei L. Targeting the kynurenine pathway-related alterations in Alzheimer's dis- ease: a future therapeutic strategy. J Alzheimers Dis. 2011;24(Suppl 2):199-209.

130 Campesan S, Green EW, Breda C, Sathyasaikumar KV, Muchowski PJ, Schwarcz R, et al. The kynurenine pathway modulates neurodegeneration in a Drosophila model of Huntington's disease. Curr Biol. 2011;21(11): 961-6.

131 Thevandavakkam MA, Schwarcz R, Muchowski PJ, Giorgini F. Targeting kynurenine 3-monooxygenase (KMO): implications for therapy in Huntington's disease. CNS Neurol Disord Drug Targets. 2010; 9(6):791-800

132 Havelund JF, Andersen AD, Binzer M, Blaabjerg M, Heegaard NHH, Stenager E, et al. Changes in kynurenine pathway metabolism in Parkinson patients with L-DOPAinduced dyskinesia. J Neurochem. 2017; 142(5):756-66.

133 Iwaoka K, Otsuka C, Maeda T, Yamahara K, Kato K, Takahashi K, et al. Impaired metabolism of kynurenine and its metabolites in CSF of parkinson's disease. Neurosci Lett. 2020;714:134576.

134 Chen Y, Brew BJ, Guillemin GJ. Characterization of the kynurenine pathway in NSC34 cell line: implications for amyotrophic lateral sclerosis. J Neurochem. 2011;118(5): 816-25.

135 Chen Y, Stankovic R, Cullen KM, Meininger V, Garner B, Coggan S, et al. The kynurenine pathway and inflammation in amyotrophic lateral sclerosis. Neurotox Res. 2010;18(2): 132-42.

136 Tan VX, Guillemin GJ. Kynurenine pathway metabolites as biomarkers for amyotrophic lateral sclerosis. Front Neurosci. 2019;13: 1013.

137 Konstantinou G, Papageorgiou CC, Angelopoulos E. Kynurenine pathway in bipolar disorder. Psychiatriki. 2018 Oct-Dec;29(4): 338-48.

138 Maget A, Platzer M, Bengesser SA, Fellendorf FT, Birner A, Queissner R, et al. Differences in kynurenine metabolism during depressive, manic, and euthymic phases of bipolar affective disorder. Curr Top Med Chem. 2020;20(15):1344-52.

139 Tanaka M, Bohár Z, Martos D, Telegdy G, Vécsei L. Antidepressant-like effects of kynurenic acid in a modified forced swim test. Pharmacol Rep. 2020;72(2):449-55.

140 Erabi H, Okada G, Shibasaki C, Setoyama D, Kang D, Takamura M, et al. Kynurenic acid is a potential overlapped biomarker between diagnosis and treatment response for depression from metabolome analysis. Sci Rep. 2020;10(1):16822.

141 Carrillo-Mora P, Pérez-De la Cruz V, Estrada-Cortés B, Toussaint-González P, Martínez-Cortéz JA, Rodríguez-Barragán M, et al. Serum kynurenines correlate with depressive symptoms and disability in poststroke patients: a cross-sectional study. Neurorehabil Neural Repair. 2020;34(10):93644.
142 Rossignol DA, Frye RE. The use of medications approved for Alzheimer's disease in autism spectrum disorder: a systematic review. Front Pediatr. 2014;2:87.

143 Burket JA, Deutsch SI. Metabotropic functions of the NMDA receptor and an evolving rationale for exploring NR2A-selective positive allosteric modulators for the treatment of autism spectrum disorder. Prog NeuroPsychopharmacol Biol Psychiatry. 2019;90: $142-60$.

144 Scharfman HE, Goodman JH, Schwarcz R. Electrophysiological effects of exogenous and endogenous kynurenic acid in the rat brain: studies in vivo and in vitro. Amino Acids. 2000;19(1):283-97.

145 Foster AC, Vezzani A, French ED, Schwarcz R. Kynurenic acid blocks neurotoxicity and seizures induced in rats by the related brain metabolite quinolinic acid. Neurosci Lett. 1984;48(3):273-8.

146 Demeter I, Nagy K, Gellért L, Vécsei L, Fülöp F, Toldi J. A novel kynurenic acid analog (SZR104) inhibits pentylenetetrazole-induced epileptiform seizures. An electrophysiological study: special issue related to kynurenine. J Neural Transm. 2012;119(2):151-4

147 Yan EB, Frugier T, Lim CK, Heng B, Sundaram G, Tan M, et al. Activation of the kynurenine pathway and increased production of the excitotoxin quinolinic acid following traumatic brain injury in humans. J Neuroinflammation. 2015;12:110.

148 Jacobs KR, Lovejoy DB. Inhibiting the kynurenine pathway in spinal cord injury: multiple therapeutic potentials?. Neural Regen Res. 2018;13(12):2073-6.

149 Koola MM. Galantamine-memantine combination for cognitive impairments due to electroconvulsive therapy, Traumatic Brain injury, and neurologic and psychiatric disorders: kynurenic acid and mismatch negativity target engagement. Prim Care Companion CNS Disord. 2018;20(2):17nr02235.[

150 de Bie J, Guest J, Guillemin GJ, Grant R. Central kynurenine pathway shift with age in women. J Neurochem. 2016;136(5):9951003.

151 Jovanovic F, Candido KD, Knezevic NN The role of the kynurenine signaling pathway in different chronic pain conditions and potential use of therapeutic agents. Int J Mol Sci. 2020;21(17):6045.

152 Fujigaki H, Yamamoto Y, Saito K. L-Tryptophan-kynurenine pathway enzymes are therapeutic target for neuropsychiatric diseases: focus on cell type differences. Neuropharmacology. 2017;112(Pt B):264-74.:

153 Maddison DC, Giorgini F. The kynurenine pathway and neurodegenerative disease. Semin Cell Dev Biol. 2015;40:134-41.

154 Koshy Cherian A, Gritton H, Johnson DE, Young D, Kozak R, Sarter M. A systemicallyavailable kynurenine aminotransferase II (KAT II) inhibitor restores nicotine-evoked glutamatergic activity in the cortex of rats. Neuropharmacology. 2014;82:41-8. 
155 Potter MC, Elmer GI, Bergeron R, Albuquerque EX, Guidetti P, Wu HQ, et al. Reduction of endogenous kynurenic acid formation enhances extracellular glutamate, hippocampal plasticity, and cognitive behavior. Neuropsychopharmacology. 2010; 35(8):1734-42.

156 Yu P, Di Prospero NA, Sapko MT, Cai T, Chen A, Melendez-Ferro M, et al. Biochemical and phenotypic abnormalities in kynurenine aminotransferase II-deficient mice. Mol Cell Biol. 2004;24(16):6919-30.

157 Nematollahi A, Sun G, Jayawickrama GS, Church WB. Kynurenine aminotransferase Isozyme inhibitors: a review. Int J Mol Sci. 2016;17(6):946. [

158 Réus GZ, Becker IRT, Scaini G, Petronilho F, Oses JP, Kaddurah-Daouk R, et al. The inhibition of the kynurenine pathway prevents behavioral disturbances and oxidative stress in the brain of adult rats subjected to an animal model of schizophrenia. Prog Neuropsychopharmacol Biol Psychiatry. 2018;81: 55-63.

159 Yu D, Tao BB, Yang YY, Du LS, Yang SS, He $\mathrm{XJ}$, et al. The IDO inhibitor coptisine ameliorates cognitive impairment in a mouse model of Alzheimer's disease. J Alzheimers Dis. 2015;43(1):291-302.

160 Yu CJ, Zheng MF, Kuang CX, Huang WD, Yang Q. Oren-gedoku-to and its constituents with therapeutic potential in Alzheimer's disease inhibit indoleamine 2, 3-dioxygenase activity in vitro. J Alzheimers Dis. 2010;22(1):257-66.

161 Liu M, Wang X, Wang L, Ma X, Gong Z, Zhang S, et al. Targeting the IDO1 pathway in cancer: from bench to bedside. J Hematol Oncol. 2018;11(1):100.

162 Sforzini L, Nettis MA, Mondelli V, Pariante $\mathrm{CM}$. Inflammation in cancer and depression: a starring role for the kynurenine pathway. Psychopharmacology. 2019;236(10): 2997-3011.
163 Zhai L, Spranger S, Binder DC, Gritsina G, Lauing KL, Giles FJ, et al. Molecular pathways: targeting IDO1 and other tryptophan dioxygenases for cancer immunotherapy. Clin Cancer Res. 2015;21(24):5427-33.

164 Zwilling D, Huang SY, Sathyasaikumar KV, Notarangelo FM, Guidetti P, Wu HQ, et al. Kynurenine 3-monooxygenase inhibition in blood ameliorates neurodegeneration. Cell. 2011;145(6):863-74.

165 Tufvesson-Alm M, Schwieler L, Schwarcz R, Goiny M, Erhardt S, Engberg G. Importance of kynurenine 3-monooxygenase for spontaneous firing and pharmacological responses of midbrain dopamine neurons: relevance for schizophrenia. Neuropharmacology. 2018;138:130-9.

166 Giorgini F, Huang SY, Sathyasaikumar KV, Notarangelo FM, Thomas MA, Tararina M, et al. Targeted deletion of kynurenine 3-monooxygenase in mice: a new tool for studying kynurenine pathway metabolism in periphery and brain. J Biol Chem. 2013;288(51): 36554-66.

167 Erhardt S, Pocivavsek A, Repici M, Liu XC, Imbeault S, Maddison DC, et al. Adaptive and behavioral changes in kynurenine 3-monooxygenase knockout mice: relevance to psychotic disorders. Biol Psychiatry. 2017;82(10):756-65.

168 Pellicciari R, Amori L, Costantino G, Giordani A, Macchiarulo A, Mattoli L, et al. Modulation of the kynurine pathway of tryptophan metabolism in search for neuroprotective agents. Focus on kynurenine3-hydroxylase. Adv Exp Med Biol. 2003;527: 621-8.

169 Peters O, Lorenz D, Fesche A, Schmidtke K Hüll M, Perneczky R, et al. A combination of galantamine and memantine modifies cognitive function in subjects with amnestic MCI. J Nutr Health Aging. 2012;16(6):5448.
170 Matsuzono K, Hishikawa N, Ohta Y, Yamashita T, Deguchi K, Nakano Y, et al. Combination therapy of cholinesterase inhibitor (Donepezil or Galantamine) plus memantine in the okayama memantine study. J Alzheimers Dis. 2015;45(3):771-80.:

171 Li DD, Zhang YH, Zhang W, Zhao P. Metaanalysis of randomized controlled trials on the efficacy and safety of Donepezil, galantamine, rivastigmine, and memantine for the treatment of Alzheimer's disease. Front Neurosci. 2019;13:472.

172 Koola MM, Looney SW, Hong H, Pillai A, Hou W. Meta-analysis of randomized controlled trials of galantamine in schizophrenia: significant cognitive enhancement. Psychiatry Res. 2020;291:113285.

173 Kishi T, Matsuda Y, Iwata N. Memantine add-on to antipsychotic treatment for residual negative and cognitive symptoms of schizophrenia: a meta-analysis. Psychopharmacology. 2017;234(14):2113-25.

174 Koola MM, Buchanan RW, Pillai A, Aitchison KJ, Weinberger DR, Aaronson ST, et al. Potential role of the combination of galantamine and memantine to improve cognition in schizophrenia. Schizophr Res. 2014; 157(1-3):84-9.

175 Koola MM. Potential role of antipsychoticgalantamine-memantine combination in the treatment of positive, cognitive, and negative symptoms of schizophrenia. Mol Neuropsychiatry. 2018;4(3):134-48.

176 Koola MM. Antipsychotic-minocyclineacetylcysteine combination for positive, cognitive, and negative symptoms of schizophrenia. Asian J Psychiatr. 2019;40:100-2.

177 Muzik O, Burghardt P, Yi Z, Kumar A, Seyoum B. Successful metformin treatment of insulin resistance is associated with downregulation of the kynurenine pathway. Biochem Biophys Res Commun. 2017;488(1): 29-32. 